Article

\title{
Incidence, Persistence, and Clearance of Anal Human Papillomavirus among Men Who Have Sex with Men in China: An Observational Cohort Study
}

Yiguo Zhou ${ }^{1,+} \mathbb{D}^{D}$, Xinyi Zhou ${ }^{1,+}$, Yi-Fan Lin ${ }^{1}$, Ganfeng Luo ${ }^{1}$, Yong Lu ${ }^{2,3}$, Zhenyu Wang ${ }^{2}$, Peiyang Li ${ }^{2}$, Zhenzhou Luo ${ }^{4}$, Xiaojun Meng ${ }^{5}$, Tian Tian ${ }^{1}$, Leiwen Fu ${ }^{1}$, Jianghong Dai ${ }^{6}$ and Huachun Zou ${ }^{1,7}, * \mathbb{D}$

1 School of Public Health (Shenzhen), Sun Yat-sen University, Shenzhen 518107, China; zhouyg5@mail2.sysu.edu.cn (Y.Z.); zhouxy257@mail2.sysu.edu.cn (X.Z.); linyf5@mail.sysu.edu.cn (Y.-F.L.); luogf6@mail2.sysu.edu.cn (G.L.); tiant65@mail.sysu.edu.cn (T.T.); fulw3@mail2.sysu.edu.cn (L.F.)

2 School of Public Health, Sun Yat-sen University, Guangzhou 510006, China; luyong@mail2.sysu.edu.cn (Y.L.); wangzhy39@mail2.sysu.edu.cn (Z.W.); lipy26@mail2.sysu.edu.cn (P.L.)

3 School of Public Health, Guizhou Medical University, Guiyang 550025, China

4 Shenzhen Nanshan Center for Chronic Disease Control, Shenzhen 518000, China; paulluo9909@163.com

5 Wuxi Municipal Centre for Disease Control and Prevention, Wuxi 214023, China; mengxiaojunwx@163.com

6 School of Public Health, Xinjiang Medical University, Urumqi 830011, China; epidjh@163.com

7 Kirby Institute, University of New South Wales, Sydney, NSW 2052, Australia

* Correspondence: zouhuachun@mail.sysu.edu.cn; Tel.: +86-20-8733-5651

+ These authors contributed equally to this work.

Citation: Zhou, Y.; Zhou, X.; Lin, Y.-F.; Luo, G.; Lu, Y.; Wang, Z.; Li, P.; Luo, Z.; Meng, X.; Tian, T.; et al. Incidence, Persistence, and Clearance of Anal Human Papillomavirus among Men Who Have Sex with Men in China: An Observational Cohort Study. Pathogens 2022, 11, 314. https://doi.org/10.3390/ pathogens11030314

Academic Editor: María-Teresa Pérez-Gracia

Received: 21 January 2022

Accepted: 1 March 2022

Published: 3 March 2022

Publisher's Note: MDPI stays neutral with regard to jurisdictional claims in published maps and institutional affiliations.

Copyright: (C) 2022 by the authors. Licensee MDPI, Basel, Switzerland. This article is an open access article distributed under the terms and conditions of the Creative Commons Attribution (CC BY) license (https:// creativecommons.org/licenses/by/ $4.0 /)$.

\begin{abstract}
Background: We conducted a prospective observational cohort study to measure incidence, persistence, and clearance of anal human papillomavirus (HPV) among men who have sex with men (MSM) in China. (2) Methods: MSM were recruited in Guangzhou, Shenzhen and Wuxi, China in 2017. A tablet-based questionnaire was used to collect sociodemographic and behavioral characteristics. An anal brush sample was collected for HPV testing and genotyping. Participants were followed up 12 months after enrolment. (3) Results: A total of 196 participants completed two HPV tests with a median age of 27.3 (interquartile range (IQR) 24.0-32.8) years. Rate of incidence, persistence, and clearance for HPV among MSM were 31.3 (95\% confidence interval (CI) 24.7-39.2), 47.9 (36.8-61.3), and 122.5 (104.3-143.0) per 1000 person months (pm), respectively. HPV 16 $(4.1 / 1000 \mathrm{pm})$ had the highest incidence rate, and HPV $6(47.4 / 1000 \mathrm{pm})$ had the highest persistence rate. Having lower education and engaging in receptive anal intercourse were potential risk factors of HPV incidence. A higher incidence rate was observed among younger MSM. (4) Conclusions: The high incidence and low clearance of anal HPV highlight the necessity of HPV vaccination among MSM. Further studies are needed to clarify the HPV dynamics at multiple anatomical sites and the burden of HPV-related diseases among MSM.
\end{abstract}

Keywords: human papillomavirus; men who have sex with men; incidence; persistence; clearance

\section{Introduction}

Anal cancer, with increased incidence in recent decades in many countries [1-6], is mostly caused by persistent infection with high-risk genotypes of human papillomavirus (HPV), particularly HPV 16 [7]. While the incidence of anal cancer is relatively rare among women and heterosexual men, it is particularly high among men who have sex with men (MSM) and bisexual men, with an incidence up to 15.5 times higher than that among heterosexual men [8]. Human immunodeficiency virus (HIV) infection is an acknowledged factor associated with higher incidence of HPV-related morbidities among MSM [9-11].

It was estimated that the incidence of anal cancer was 85 and 19 per 100,000 person years for HIV-positive and HIV-negative MSM, respectively [12]. MSM also have higher rates of HPV infection than heterosexual men and women [13,14]. A global systematic 
review and meta-analysis found that $30 \%$ of HIV-positive MSM and $14 \%$ of HIV-negative MSM were infected with HPV 16, while this was only $11 \%$ and 3\% in HIV-positive and HIV-negative heterosexual men, respectively [13].

HPV vaccination is effective in preventing HPV-related diseases, including anal cancer [15]. While an increasing number of countries are introducing HPV vaccination programs targeting men or MSM [16-18], most countries, China included, continue to limit HPV vaccination to women. MSM likely do not benefit from the herd immunity protection that vaccination efforts targeting women provide to heterosexual men [19]. In order to inform HPV vaccination policies for MSM, it is essential to reveal the basic epidemiological characteristics of HPV infection, including HPV prevalence, incidence, persistence, and clearance.

Incidence, persistence, and clearance of HPV among MSM has been reported in several studies conducted in high-income countries, including Spain and The Netherlands $[11,20]$. However, to our knowledge, there have been no previously published studies reporting HPV incidence or clearance among MSM in China. To better understand the natural history of HPV among MSM and inform effective HPV vaccination strategies, we conducted a longitudinal study to investigate the incidence, persistence, and clearance of 37 genotypes of anal HPV among MSM recruited from three metropolitan cities in China.

\section{Results}

\subsection{Population Characteristics}

A total of 196 participants completed two HPV tests, accounting for $36.5 \%(196 / 537)$ of MSM tested for HPV at baseline. Of the 196 men who completed two HPV tests, 14 (7.1\%) were HIV-positive at baseline, and the median time interval between two HPV tests was 12.4 months. More than half were aged 20-29 years, enrolled from Guangzhou, white-collar workers, and unmarried, and had a monthly salary $\geq$ CNY 5000, $\geq 6$ sexual partners in lifetime, and $\geq 3$ years of sexual experience. Sociodemographic and behavioral characteristics comparing MSM who completed two HPV tests and MSM only tested at baseline are presented in Table S1 (Supplementary Materials). MSM who completed two HPV tests were older (median age 27.3 (IQR 24.0-32.8) years vs. 25.7 (22.2-29.8) years, $p<0.001$ ), more likely to be recruited from Shenzhen, and less likely to be recruited from Wuxi than men who were only tested at baseline. All other measured sociodemographic characteristics and sexual health behaviors did not differ significantly between the two groups.

\subsection{Incidence, Clearance, and Persistence of Anal HPV among MSM}

Genotype-specific rates of anal HPV incidence, clearance, and persistence are shown in Table 1. Among the 196 MSM who completed two HPV tests, 105 MSM were infected with anal infections with any HPV genotype (a total of 224 infections) at baseline, and 80 MSM were infected with anal infections with any genotype (a total of 140 infections) at 12 months. The average number of genotypes detected for each individual decreased from 2.13 at baseline to 1.75 at 12 months.

Seventy-seven incident infections were observed. Rates of incidence for any HPV, any high-risk HPV, and any nonavalent vaccine-preventable HPV among MSM were 31.3 (95\% CI 24.7-39.2), 17.1 (12.3-23.1), and 14.2 (9.9-19.8) per 1000 person months (pm), respectively. The five HPV genotypes that caused the most incident infections were HPV 16 (4.1/1000 pm), 52 (3.1/1000 pm), 18 (2.1/1000 pm), 58 (1.8/1000 pm), and 11 (1.8/1000 pm). 
Table 1. Incidence/persistence/clearance of anal HPV infection among men who have sex with men.

\begin{tabular}{|c|c|c|c|c|c|c|c|c|c|}
\hline HPV Genotypes & $\begin{array}{l}\text { Incident } \\
\text { Infections }\end{array}$ & $\begin{array}{l}\text { Person } \\
\text { Months }\end{array}$ & $\begin{array}{c}\text { Incidence/1000 Person } \\
\text { Months }(95 \% \mathrm{CI})\end{array}$ & $\begin{array}{l}\text { Persistent } \\
\text { Infections }\end{array}$ & $\begin{array}{l}\text { Person } \\
\text { Months }\end{array}$ & $\begin{array}{l}\text { Persistence } / 1000 \text { Person } \\
\text { Months }(95 \% \text { CI })\end{array}$ & $\begin{array}{l}\text { Cleared } \\
\text { Infections }\end{array}$ & $\begin{array}{l}\text { Person } \\
\text { Months }\end{array}$ & $\begin{array}{c}\text { Clearance } / 1000 \text { Person } \\
\text { Months }(95 \% \text { CI })\end{array}$ \\
\hline Any genotype ${ }^{a}$ & 77 & 2457 & $31.3(24.7-39.2)$ & 63 & 1314 & $47.9(36.8-61.3)$ & 161 & 1314 & $122.5(104.3-143.0)$ \\
\hline \multicolumn{10}{|l|}{ HR genotypes } \\
\hline Any HR genotype & 42 & 2457 & $17.1(12.3-23.1)$ & 38 & 922 & $41.2(29.2-56.6)$ & 81 & 922 & $87.9(69.8-109.2)$ \\
\hline HPV 16 & 9 & 2187 & $4.1(1.9-7.8)$ & 8 & 271 & $29.5(12.7-58.2)$ & 14 & 271 & $51.7(28.2-86.7)$ \\
\hline HPV 18 & 5 & 2353 & $2.1(0.7-5.0)$ & 0 & 104 & $0.0(0.0-35.5)$ & 8 & 104 & 76.9 (33.2-151.6) \\
\hline HPV 33 & 3 & 2409 & $1.2(0.3-3.6)$ & 2 & 48 & $41.7(5.0-150.5)$ & 2 & 48 & $41.7(5.0-150.5)$ \\
\hline HPV 35 & 1 & 2409 & $0.4(0.0-2.3)$ & 1 & 48 & $20.8(0.5-116.1)$ & 3 & 48 & $62.5(12.9-182.7)$ \\
\hline HPV 39 & 3 & 2364 & $1.3(0.3-3.7)$ & 4 & 93 & $43.0(11.7-110.1)$ & 5 & 93 & $53.8(17.5-125.5)$ \\
\hline HPV 45 & 1 & 2380 & $0.4(0.0-2.3)$ & 1 & 77 & $13.0(0.3-72.4)$ & 5 & 77 & $64.9(21.1-151.5)$ \\
\hline HPV 51 & 4 & 2296 & $1.7(0.5-4.5)$ & 6 & 161 & $37.3(13.7-81.1)$ & 6 & 161 & $37.3(13.7-81.1)$ \\
\hline HPV 52 & 7 & 2223 & $3.1(1.3-6.5)$ & 4 & 234 & $17.1(4.7-43.8)$ & 14 & 234 & $59.8(32.7-100.4)$ \\
\hline HPV 58 & 4 & 2271 & $1.8(0.5-4.5)$ & 8 & 186 & $43.0(18.6-84.7)$ & 8 & 186 & $43.0(18.6-84.7)$ \\
\hline HPV 59 & 2 & 2382 & $0.8(0.1-3.0)$ & 1 & 76 & $13.2(0.3-73.3)$ & 4 & 76 & $52.6(14.3-134.8)$ \\
\hline HPV 68 & 2 & 2339 & $0.9(0.1-3.1)$ & 3 & 118 & $25.4(5.2-74.3)$ & 7 & 118 & $59.3(23.9-122.2)$ \\
\hline \multicolumn{10}{|l|}{ LR genotypes } \\
\hline Any LR genotype & 35 & 2457 & $14.2(9.9-19.8)$ & 25 & 902 & $27.7(17.9-40.9)$ & 80 & 902 & $88.7(70.3-110.4)$ \\
\hline HPV 6 & 2 & 2246 & $0.9(0.1-3.2)$ & 10 & 211 & $47.4(22.7-87.2)$ & 8 & 211 & $37.9(16.4-74.7)$ \\
\hline HPV 11 & 4 & 2239 & $1.8(0.5-4.6)$ & 4 & 218 & $18.3(5.0-47.0)$ & 12 & 218 & $55.0(28.4-96.2)$ \\
\hline HPV 26 & 1 & 2447 & $0.4(0.0-2.3)$ & 0 & 11 & $0.0(0.0-335.4)$ & 1 & 11 & $90.9(2.3-506.5)$ \\
\hline HPV 34 & 1 & 2443 & $0.4(0.0-2.3)$ & 0 & 14 & $0.0(0.0-263.5)$ & 1 & 14 & $71.4(1.8-398.0)$ \\
\hline HPV 40 & 3 & 2375 & $1.3(0.3-3.7)$ & 2 & 82 & $24.4(3.0-88.1)$ & 4 & 82 & $48.8(13.3-124.9)$ \\
\hline HPV 42 & 3 & 2339 & $1.3(0.3-3.7)$ & 3 & 118 & $25.4(5.2-74.3)$ & 9 & 118 & $76.3(34.9-144.8)$ \\
\hline
\end{tabular}


Table 1. Cont.

\begin{tabular}{|c|c|c|c|c|c|c|c|c|c|}
\hline HPV Genotypes & $\begin{array}{l}\text { Incident } \\
\text { Infections }\end{array}$ & $\begin{array}{l}\text { Person } \\
\text { Months }\end{array}$ & $\begin{array}{l}\text { Incidence/1000 Person } \\
\text { Months (95\% CI) }\end{array}$ & $\begin{array}{l}\text { Persistent } \\
\text { Infections }\end{array}$ & $\begin{array}{l}\text { Person } \\
\text { Months }\end{array}$ & $\begin{array}{l}\text { Persistence/1000 Person } \\
\text { Months }(95 \% \text { CI) }\end{array}$ & $\begin{array}{l}\text { Cleared } \\
\text { Infections }\end{array}$ & $\begin{array}{l}\text { Person } \\
\text { Months }\end{array}$ & $\begin{array}{l}\text { Clearance/1000 Person } \\
\text { Months }(95 \% \text { CI) }\end{array}$ \\
\hline HPV 43 & 2 & 2356 & $0.8(0.1-3.1)$ & 1 & 101 & $9.9(0.3-55.2)$ & 7 & 101 & $69.3(27.9-142.8)$ \\
\hline HPV 44 & 0 & 2457 & $0.0(0.0-1.5)$ & 0 & 0 & NA & 0 & 0 & NA \\
\hline HPV 53 & 3 & 2405 & $1.2(0.3-3.6)$ & 0 & 53 & $0.0(0.0-69.6)$ & 4 & 53 & $75.5(20.6-193.2)$ \\
\hline HPV 54 & 0 & 2446 & $0.0(0.0-1.5)$ & 0 & 11 & $0.0(0.0-335.4)$ & 1 & 11 & $90.9(2.3-506.5)$ \\
\hline HPV 55 & 1 & 2457 & $0.4(0.0-2.3)$ & 0 & 0 & NA & 0 & 0 & NA \\
\hline HPV 61 & 3 & 2444 & $1.2(0.3-3.6)$ & 0 & 13 & $0.0(0.0-283.8)$ & 1 & 13 & $76.9(1.9-428.6)$ \\
\hline HPV 66 & 2 & 2424 & $0.8(0.1-3.0)$ & 0 & 34 & $0.0(0.0-108.5)$ & 3 & 34 & $88.2(18.2-257.9)$ \\
\hline HPV 67 & 2 & 2435 & $0.8(0.1-3.0)$ & 0 & 22 & $0.0(0.0-167.7)$ & 2 & 22 & $90.9(11.0-328.4)$ \\
\hline HPV 69 & 1 & 2428 & $0.4(0.0-2.3)$ & 1 & 29 & $34.5(0.9-192.1)$ & 1 & 29 & $34.5(0.9-192.1)$ \\
\hline HPV 70 & 0 & 2443 & $0.0(0.0-1.5)$ & 0 & 14 & $0.0(0.0-263.5)$ & 1 & 14 & $71.4(1.8-398.0)$ \\
\hline HPV 71 & 0 & 2443 & $0.0(0.0-1.5)$ & 0 & 14 & $0.0(0.0-263.5)$ & 1 & 14 & $71.4(1.8-398.0)$ \\
\hline HPV 73 & 0 & 2421 & $0.0(0.0-1.5)$ & 1 & 36 & $27.8(0.7-154.8)$ & 3 & 36 & $83.3(17.2-243.5)$ \\
\hline HPV 81 & 3 & 2429 & $1.2(0.3-3.6)$ & 1 & 28 & $35.7(0.9-199.0)$ & 2 & 28 & $71.4(8.7-258.0)$ \\
\hline HPV 82 & 2 & 2348 & $0.9(0.1-3.1)$ & 2 & 110 & $18.2(2.2-65.7)$ & 6 & 110 & $54.5(20.0-118.7)$ \\
\hline HPV 83 & 0 & 2445 & $0.0(0.0-1.5)$ & 0 & 12 & $0.0(0.0-307.4)$ & 1 & 12 & $83.3(2.1-464.3)$ \\
\hline HPV 84 & 2 & 2318 & $0.9(0.1-3.1)$ & 0 & 139 & $0.0(0.0-26.5)$ & 11 & 139 & $79.1(39.5-141.6)$ \\
\hline \multicolumn{10}{|c|}{ Vaccine-preventable genotypes } \\
\hline $9 \mathrm{~V}$ genotypes ${ }^{b}$ & 35 & 2457 & $14.2(9.9-19.8)$ & 37 & 902 & $41.0(28.9-56.5)$ & 73 & 902 & $80.9(63.4-101.8)$ \\
\hline $4 \mathrm{~V}$ genotypes ${ }^{\mathrm{c}}$ & 20 & 2457 & $8.1(5.0-12.6)$ & 22 & 687 & $32.0(20.1-48.5)$ & 42 & 687 & $61.1(44.1-82.6)$ \\
\hline $2 \mathrm{~V}$ genotypes ${ }^{\mathrm{d}}$ & 14 & 2408 & $5.8(3.2-9.8)$ & 8 & 325 & $24.6(10.6-48.5)$ & 22 & 325 & $67.7(42.4-102.5)$ \\
\hline HPV 6/11 & 6 & 2457 & $2.4(0.9-5.3)$ & 14 & 429 & $32.6(17.8-54.8)$ & 20 & 429 & $46.6(28.5-72.0)$ \\
\hline
\end{tabular}

Abbreviations: HPV, human papillomavirus; CI, confidence interval; HR, high-risk; LR, low-risk; NA, not available; ${ }^{a} \geq 1$ of the 37 genotypes were detected; ${ }^{b}$ 9V genotypes include HPV $6,11,16,18,31,33,45,52$, and $58 ;{ }^{c} 4 \mathrm{~V}$ genotypes include HPV $6,11,16$, and $18{ }^{\mathrm{d}}{ }^{2} \mathrm{~V}$ genotypes include HPV 16 and 18. 
Sixty-three persistent infections were observed. Rates of persistence for any HPV, any high-risk HPV, and any nonavalent vaccine-preventable HPV among MSM were 47.9 (95\% CI 36.8-61.3), 41.2 (29.2-56.6), and 41.0 (28.9-56.5) per 1000 pm, respectively. The five HPV genotypes responsible for the most persistent infections were HPV 6 (47.4/1000 pm), 39 (43.0/1000 pm), 58 (43.0/1000 pm), 33 (41.7/1000 pm), and 51 (37.3/1000 pm).

A total of 161 cleared infections were observed. Rates of clearance for any HPV, any high-risk HPV, and any nonavalent vaccine-preventable HPV among MSM were 122.5 (95\% CI 104.3-143.0), 87.9 (69.8-109.2), and 80.9 (63.4-101.8) per 1000 pm, respectively. The five HPV genotypes that were most frequently cleared during the 12-month follow-up period were HPV 26 (90.9/1000 pm), 67 (90.9/1000 pm), 54 (90.9/1000 pm), 66 (88.2/1000 pm), and $31(87.0 / 1000 \mathrm{pm})$.

Among all participants, $60(30.6 \%)$ men had persistent infection with any HPV genotype, 45 (23.0\%) men infected with HPV at baseline cleared all infections at follow-up, 20 $(10.2 \%)$ men with no anal HPV infection at baseline had acquired HPV at follow-up, and 71 (36.2\%) men had no evidence of anal HPV infection at baseline and follow-up. More than half $(109,55.6 \%)$ of all men were infected with a high-risk HPV genotype at one or both timepoints. HPV 16 (9/174), 52 (7/178), and 18 (5/188) were the most common incident genotypes. HPV $6(10 / 18), 16(8 / 22)$, and $58(8 / 16)$ were the most common persistent genotypes. HPV 16 (14/22), 52 (14/18), 11 (12/16), and 84 (11/11) were the most common cleared genotypes. HPV18 and HPV84 infections at baseline achieved 100\% clearance, while only $63.6 \%, 44.4 \%$, and $75.0 \%$ of infections with HPV16, HPV6, and HPV11 were cleared, respectively. Distribution of incident, persistent, and cleared infections for each HPV genotype among all participants is shown in Figure 1.

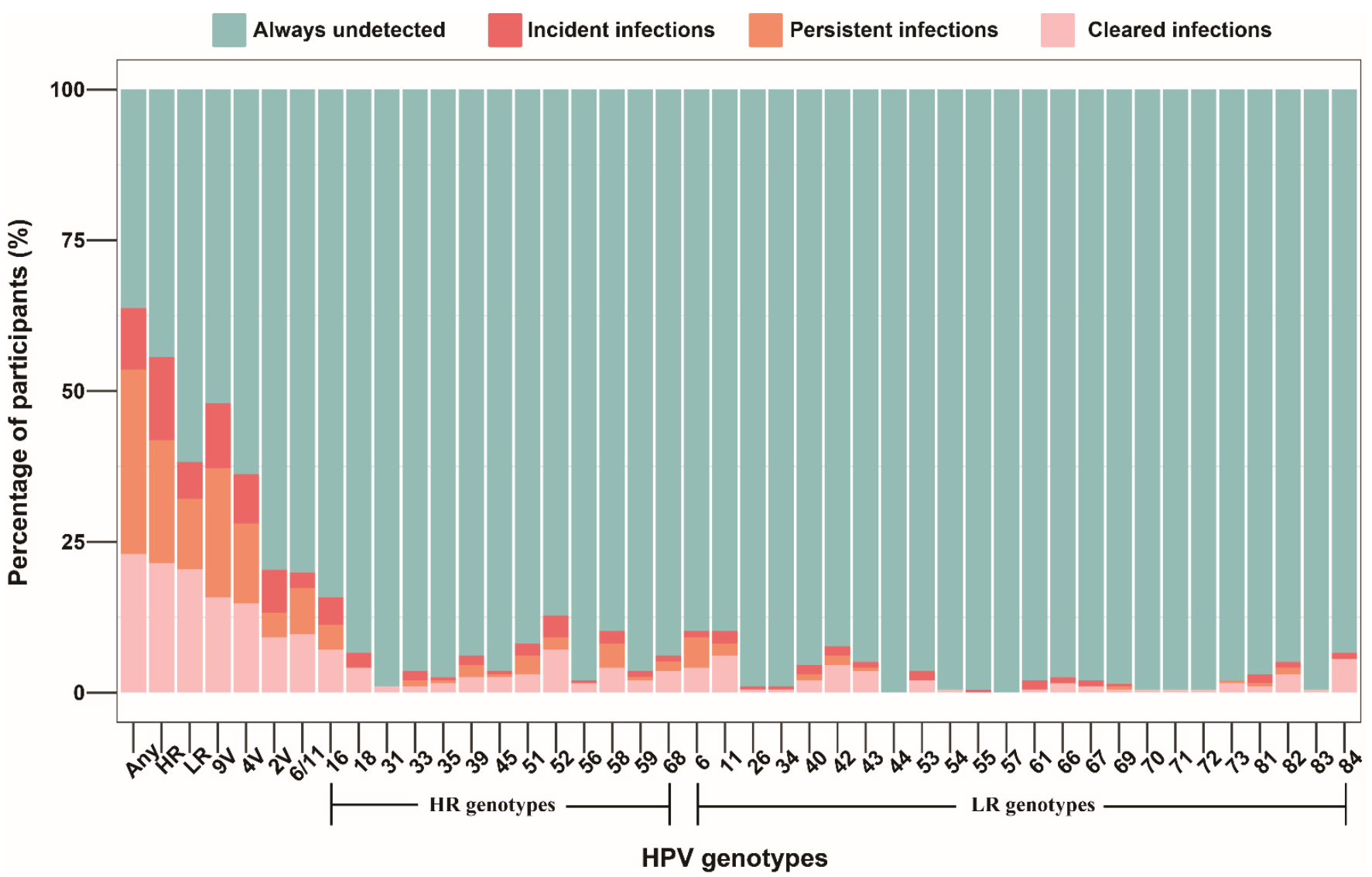

Figure 1. Distribution of incident, persistent, and cleared infections for genotype-specific HPV among 196 MSM who completed two HPV tests. Abbreviations: MSM, men who have sex with men; HPV, human papillomavirus; Any, any genotype; HR, high-risk; LR, low-risk; 9V, nonavalent vaccine-preventable; $4 \mathrm{~V}$, quadrivalent vaccine-preventable; $2 \mathrm{~V}$, bivalent vaccine-preventable. 


\subsection{Factors Associated with Anal HPV Incidence and Clearance among MSM}

Age at recruitment, educational level, and profession were associated with HPV incidence in the univariate model. In the multivariable model, those who had at least a university education (adjusted OR, $0.36 ; 95 \% \mathrm{CI}, 0.20-0.64$ ) were less likely to acquire anal HPV compared to men who had not attended university. Men who engaged in receptive anal intercourse (adjusted OR, 2.12; 95\% CI, 1.10-4.09) were more likely to have incident anal HPV compared to men who did not engage in receptive anal intercourse. Age at recruitment, site of enrollment, and profession were associated with HPV clearance in the univariate model. In the multivariable model, men aged $\geq 33$ years (adjusted OR, 2.17; $95 \% \mathrm{CI}, 1.13-4.18$ ) were less likely to clear HPV infection compared to men aged $<23$ years. Men enrolled from Wuxi (adjusted OR, 1.67; 95\% CI, 1.04-2.68) and men had a profession of teacher/institution staff (adjusted OR, 2.20; $95 \%$ CI, 1.30-3.72) were more likely to clear HPV infection compared to men enrolled from Guangzhou and men with white collar employment, respectively. Results of univariate and multivariable analyses on incidence and clearance of anal infection with any HPV genotype among MSM are shown in Table 2.

Incident anal HPV infection was highest in men aged $<23$ years $(45.0 / 1000 \mathrm{pm})$, followed by men aged $\geq 33$ years $(35.8 / 1000 \mathrm{pm})$, and lowest in men aged 23-27 years $(23.1 / 1000 \mathrm{pm})$. A similar trend was observed in incident infection with low-risk HPV genotypes, with the highest incidence rate $(26.0 / 1000 \mathrm{pm})$ among men $<23$ years and the lowest rate $(6.1 / 1000 \mathrm{pm})$ among men aged 28-32 years. Men aged 28-32 years had the highest rate of incidence anal HPV infection with the nine genotypes prevented by the nonavalent HPV vaccine $(20.2 / 1000 \mathrm{pm})$, while men aged $23-27$ years had the lowest rate of incident infections with these genotypes (10.5/1000 pm). Men aged 28-32 years had the highest clearance rate $(146.5 / 1000 \mathrm{pm})$ and men aged $\geq 33$ years had the lowest clearance rate for infection with any HPV genotype (98.6/1000 pm). Rates of anal HPV incidence, persistence, and clearance across age groups are shown in Figure 2. 
Table 2. Crude and adjusted odds ratios for incidence/clearance of anal infection with any HPV genotype among men who have sex with men.

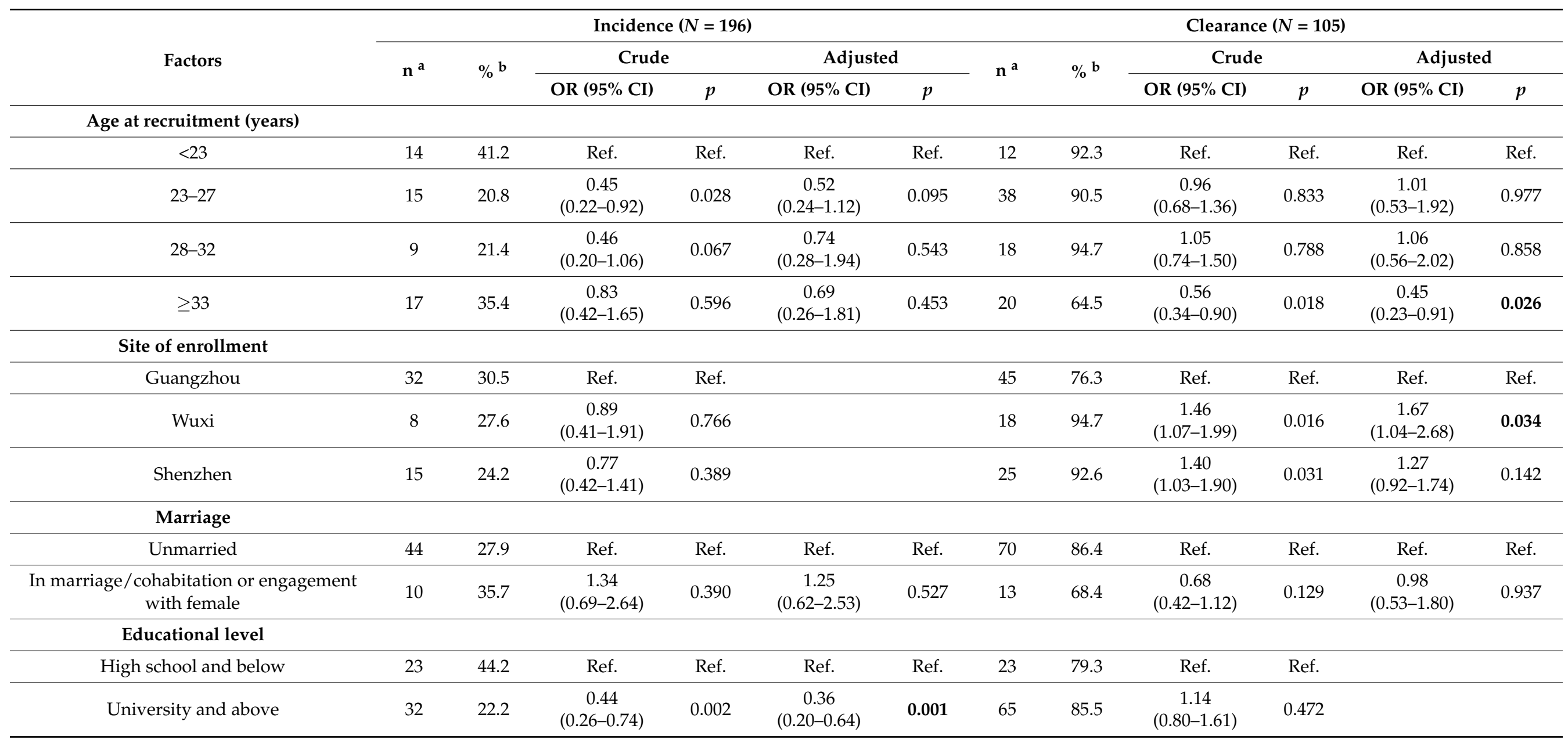


Table 2. Cont.

\begin{tabular}{|c|c|c|c|c|c|c|c|c|c|c|c|c|}
\hline \multirow{3}{*}{ Factors } & \multicolumn{6}{|c|}{ Incidence $(N=196)$} & \multicolumn{6}{|c|}{ Clearance $(N=105)$} \\
\hline & \multirow{2}{*}{$n^{a}$} & \multirow{2}{*}{$\%^{b}$} & \multicolumn{2}{|c|}{ Crude } & \multicolumn{2}{|c|}{ Adjusted } & \multirow{2}{*}{$n^{a}$} & \multirow{2}{*}{$\%^{b}$} & \multicolumn{2}{|c|}{ Crude } & \multicolumn{2}{|c|}{ Adjusted } \\
\hline & & & OR $(95 \% \mathrm{CI})$ & $p$ & OR $(95 \% \mathrm{CI})$ & $p$ & & & OR $(95 \% \mathrm{CI})$ & $p$ & OR $(95 \% \mathrm{CI})$ & $p$ \\
\hline \multicolumn{13}{|l|}{ Salary (yuan/month) } \\
\hline$<5000$ & 26 & 30.2 & Ref. & Ref. & & & 40 & 81.6 & Ref. & Ref. & & \\
\hline$\geq 5000$ & 29 & 26.4 & $\begin{array}{c}0.85 \\
(0.51-1.44)\end{array}$ & 0.550 & & & 48 & 85.7 & $\begin{array}{c}1.09 \\
(0.81-1.46)\end{array}$ & 0.575 & & \\
\hline White collar worker & 22 & 22.5 & Ref. & Ref. & Ref. & Ref. & 41 & 83.7 & Ref. & Ref. & Ref. & Ref. \\
\hline Service industry/worker & 10 & 27.0 & $\begin{array}{c}1.24 \\
(0.59-2.59)\end{array}$ & 0.576 & $\begin{array}{c}0.77 \\
(0.34-1.76)\end{array}$ & 0.535 & 20 & 87.0 & $\begin{array}{c}1.07 \\
(0.75-1.52)\end{array}$ & 0.710 & $\begin{array}{c}1.37 \\
(0.92-2.03)\end{array}$ & 0.124 \\
\hline Unemployed/self-employed & 8 & 53.3 & $\begin{array}{c}2.88 \\
(1.33-6.21)\end{array}$ & 0.007 & $\begin{array}{c}2.31 \\
(0.96-5.55)\end{array}$ & 0.061 & 4 & 57.1 & $\begin{array}{c}0.56 \\
(0.22-1.41)\end{array}$ & 0.215 & $\begin{array}{c}0.92 \\
(0.32-2.63)\end{array}$ & 0.871 \\
\hline Teacher/institution staff & 3 & 25.0 & $\begin{array}{c}1.13 \\
(0.34-3.74)\end{array}$ & 0.842 & $\begin{array}{c}1.57 \\
(0.43-5.81)\end{array}$ & 0.497 & 6 & 100.0 & $\begin{array}{c}1.39 \\
(1.12-1.72)\end{array}$ & 0.003 & $\begin{array}{c}2.20 \\
(1.30-3.72)\end{array}$ & 0.003 \\
\hline Other & 5 & 38.5 & $\begin{array}{c}1.88 \\
(0.73-4.87)\end{array}$ & 0.191 & $\begin{array}{c}2.02 \\
(0.83-4.92)\end{array}$ & 0.121 & 7 & 77.8 & $\begin{array}{c}0.88 \\
(0.48-1.63)\end{array}$ & 0.695 & $\begin{array}{c}1.34 \\
(0.74-2.44)\end{array}$ & 0.337 \\
\hline \multicolumn{13}{|c|}{ No. of sexual partners during follow-up } \\
\hline$<6$ & 30 & 31.6 & Ref. & Ref. & Ref. & Ref. & 41 & 78.9 & Ref. & Ref. & Ref. & Ref. \\
\hline$\geq 6$ & 23 & 29.1 & $\begin{array}{c}0.91 \\
(0.53-1.55)\end{array}$ & 0.726 & $\begin{array}{c}0.94 \\
(0.55-1.64)\end{array}$ & 0.839 & 36 & 87.8 & $\begin{array}{c}1.20 \\
(0.88-1.64)\end{array}$ & 0.244 & $\begin{array}{c}1.12 \\
(0.81-1.55)\end{array}$ & 0.481 \\
\hline \multicolumn{13}{|l|}{ Time since first anal sex (years) } \\
\hline$<5$ & 26 & 28.9 & Ref. & Ref. & Ref. & Ref. & 33 & 89.2 & Ref. & Ref. & Ref. & Ref. \\
\hline$\geq 5$ & 29 & 27.4 & $\begin{array}{c}0.94 \\
(0.56-1.58)\end{array}$ & 0.813 & $\begin{array}{c}1.33 \\
(0.67-2.62)\end{array}$ & 0.416 & 55 & 80.9 & $\begin{array}{c}0.84 \\
(0.64-1.12)\end{array}$ & 0.237 & $\begin{array}{c}1.07 \\
(0.78-1.48)\end{array}$ & 0.673 \\
\hline
\end{tabular}


Table 2. Cont.

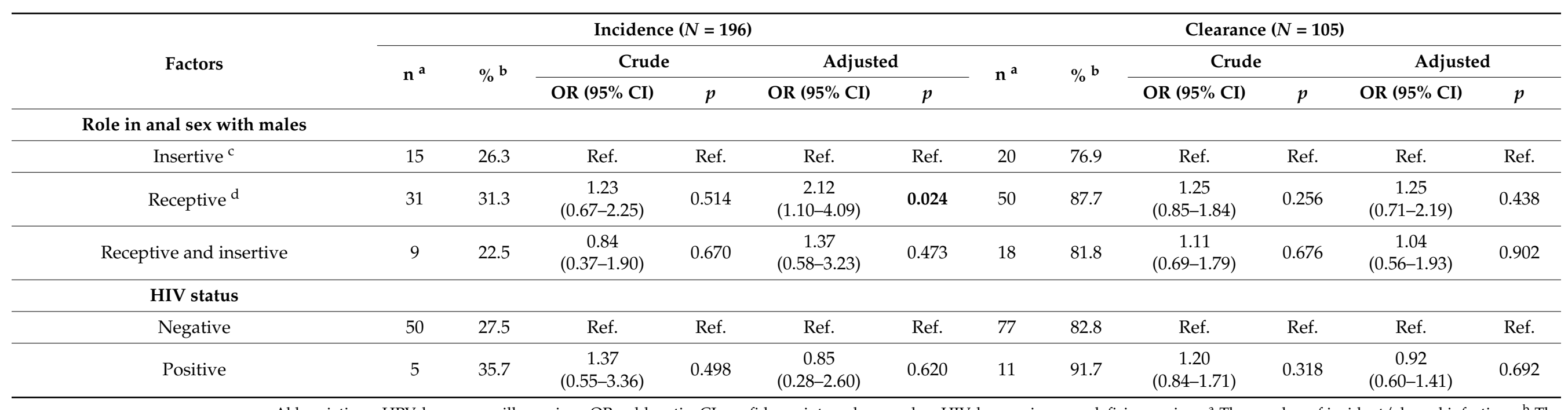

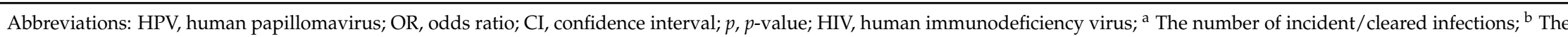
rates of incidence/clearance; ${ }^{c}$ Participant's penis in partner's anus; ${ }^{d}$ Partner's penis in participant's anus. 

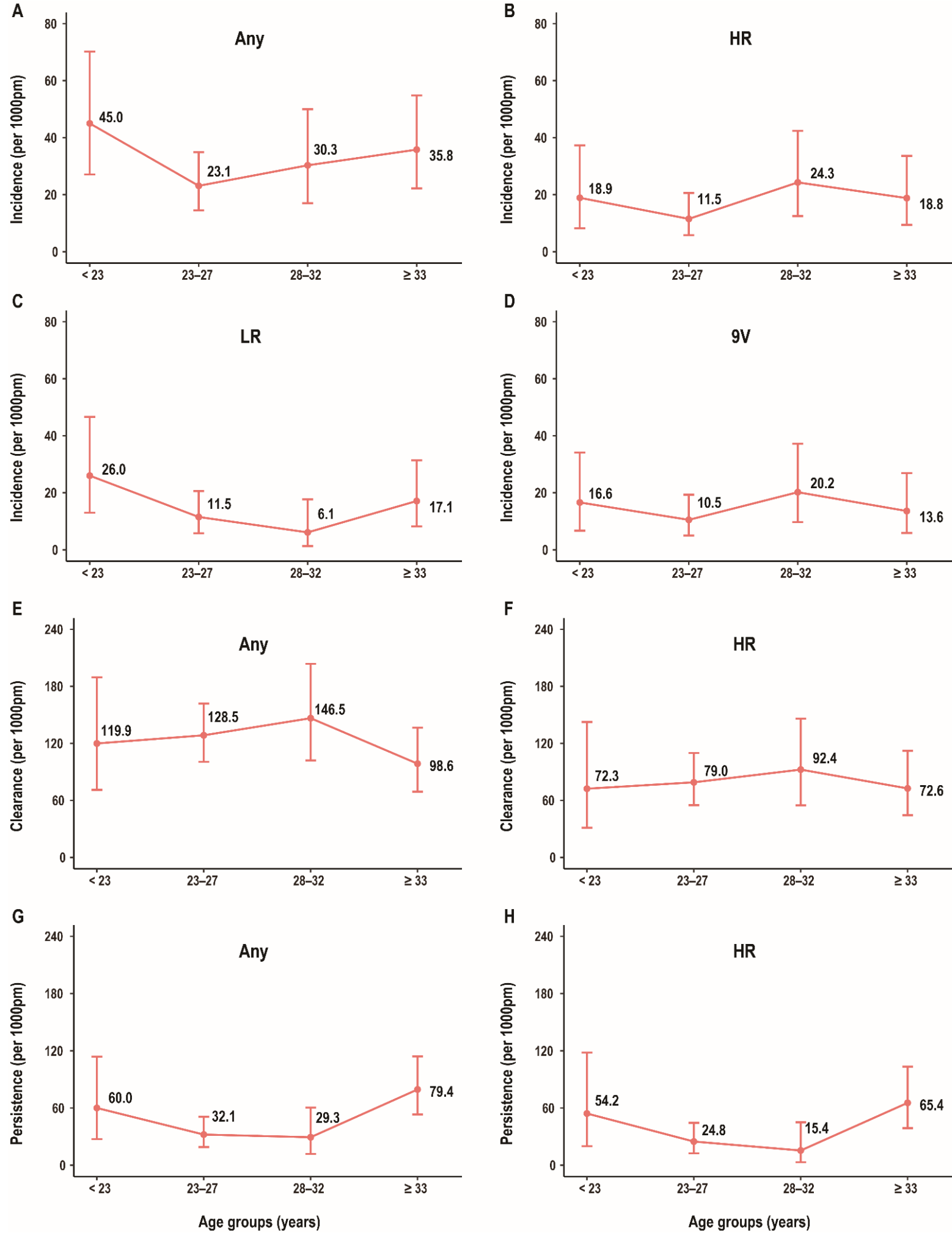

Figure 2. Distribution of rate of anal HPV incidence/persistence/clearance among age groups in MSM. Incidence rate for any genotype (A) by age; incidence rate for HR genotype (B) by age; incidence rate for LR genotype (C) by age; incidence rate for $9 \mathrm{~V}$ genotype (D) by age; clearance rate for any genotype (E) by age; clearance rate for HR genotype (F) by age; persistence rate for any genotype (G) by age; and persistence rate for HR genotype $(\mathbf{H})$ by age. Abbreviations: HPV, human papillomavirus; MSM, men who have sex with men; Any, any genotype; HR, high-risk; LR, low-risk; 9V, nonavalent vaccine-preventable. 


\section{Discussion}

This longitudinal study of 196 MSM in China attending sexual health clinics and community-based organizations is the first study to investigate the incidence, persistence, and clearance of anal HPV among MSM in China. We found high rates of incident anal HPV in this population, particularly infection with HPV16 and HPV18 genotypes. Persistence of infection with HPV6 and HPV16 genotypes was common. Over half of MSM were detected with any high-risk HPV genotype at one or both visits during our study. Incidence rates of anal HPV were higher among MSM aged $<23$ years and clearance rates of anal HPV were lower among MSM aged $\geq 33$ years.

We found the incidence of any HPV, high-risk HPV, and HPV16 at the anal site among MSM in China was 31.3, 17.1, and 4.1 per 1000 pm, respectively. Since no global systematic review and meta-analysis has been published on HPV incidence and clearance among MSM, it is hard to compare the results of our study with global averages. We can compare rates to those reported in other countries, although there are significant differences in study design, source population, and laboratory method between ours and previous studies. Incidence rates of infection with anal HPV among general MSM in this study are higher than or similar to those among HIV-negative and even HIV-positive MSM in some countries [21-24]. A study in The Netherlands reported incidence rate of infection with HPV16 was 9.1/1000 pm among HIV-positive MSM and 4.7/1000 pm among HIV-negative MSM [11]. However, some studies reported a significantly higher incidence rate than our data, with incidence rates greater than 80.0/1000 pm for anal infection with any HPV genotype [25,26]. Incidence rate of HPV among MSM varies obviously among countries, with China at a medium level in the world.

Similar to most countries, HPV16, which is the main causative agent of anal cancer, had the highest incidence rate of anal infection among MSM in China. We also found HPV16 was the most prevalent genotype among MSM in a previous cross-sectional study [27]. MSM in China may be at high risk for anal HPV lesions. As some potential transient incident infections might not have been detected during the 12-month follow-up period in this study, the true incidence rate could be higher than the rate reported here. Two cohort studies assessing HPV incidence among the general population in China have been published. Incidence rates of anal HPV among the general male population in Liuzhou City were 4.6/1000 pm for any HPV genotype and 3.5/1000 pm for high-risk HPV genotypes [28]. Incidence rates of oral HPV among the general population in rural Anyang City was $0.53 / 1000 \mathrm{pm}$ for any HPV genotype and $0.30 / 1000 \mathrm{pm}$ for high-risk HPV genotypes [29]. Thus, HPV infection among MSM might be much more common than the general male population in China. Considering the higher incidence observed among MSM $<23$ years, prophylactic HPV vaccines should be given priority to young MSM, ideally before their sexual debut.

Multiple studies in other countries have shown that HPV 16 and 18 are genotypes with the lowest rates of clearance $[11,23,25,30,31]$. In contrast, we found HPV6 had the lowest clearance rate $(37.9 / 1000 \mathrm{pm})$ among MSM in China. The clearance rate of HPV $16(51.7 / 1000 \mathrm{pm})$ in our study was similar to those reported in most of other studies $[11,23,25,30,32]$. HPV6 was also the genotype with lowest clearance rate $(94.9 / 1000 \mathrm{pm})$ in a previous longitudinal study conducted among all men in a large Chinese city; however, clearance rates of most HPV genotypes in that study were much higher than those reported here. HPV 6 may be one of the most persistent genotypes in China, which could lead to a higher disease burden of anal warts [28,33].

We found a lower level of education was associated with higher incidence of HPV infection. This risk factor for HPV infection has not been reported in previous studies. A recent systematic review and meta-analysis of HPV prevalence among MSM in China also showed MSM with a lower level of education had higher HPV prevalence [34]. MSM who have only completed primary or secondary school education may have lower health literacy, less connection to regular healthcare, or be more likely to engage in high-risk sexual behaviors. We also found an association between being teacher/institution staff 
and a higher clearance rate of anal HPV in the multivariable models, which might result from MSM with these professions usually having higher educational levels and a higher health literacy than MSM with other professions. Evy et al. found higher salary was related to persistent infection with high-risk HPV genotypes among HIV-positive MSM [23]. Alan et al. found HPV persistence was influenced by smoking and did not vary by age [35]. Ronald et al. found young HIV-positive MSM had a higher clearance rate, while age was not associated with incidence [20]. Risk factors for HPV incidence and clearance are not consistent among studies. Further investigation is needed due to the limited published literature on this issue. In the univariate model, we found a higher incidence rate of HPV in younger MSM, which might be related to the decreasing trend in the age of sexual debut among MSM in China [36]. Young MSM should be paid special attention to for containing the HPV epidemic. Meanwhile, MSM aged $\geq 33$ years were observed to have a lower clearance rate than younger MSM. It might be explained that older MSM usually had more sexual experience and more cumulative sexual partners, leading to a lower rate of clearance of HPV. More concern and health literacy for prevention of HPV infection should be conveyed to older MSM.

Our study has several limitations. First of all, only two time points of measuring were included in this study, which could not exhibit a continuous dynamic change of HPV infection among MSM and could only provide a rough estimation of epidemiological indicators. The limited number of HIV-positive MSM impeded a precise estimation of incidence and clearance rate in HIV-positive individuals. Some data were collected through self-report in questionnaires and, therefore, may be impacted by recall or social desirability biases. We did not swab the urethra or oropharynx of men in this study for HPV testing and, therefore, rates of total HPV infection among MSM were likely underestimated. Only one follow-up visit 12 months after enrollment was performed, so some transient incident infections might be missed during the follow-up. Participants willing to provide samples at two timepoints across a long follow-up period were limited, which may have affected a precise assessment of epidemiological indicators to some extent. However, the results of comparing sociodemographic and sexual behavioral characteristics between MSM tested twice and MSM tested once showed that participants retained in the follow-up might be able to represent the whole sample. In addition, this study enrolled MSM who had anal sex with two or more men in their lifetime or who had a sexually transmitted infection (STI) history, in spite of performing multiple recruitment methods, which might not represent general MSM in China. Though HPV vaccination strategies exclude men in China, some MSM might be vaccinated through other methods. HPV vaccination status was not collected in our survey, which should be involved in future studies. Moreover, beta-globin analyses were not run prior to HPV tests; therefore, it was unknown to us the number of samples providing inadequate materials for HPV testing, which might impact the estimation of $\mathrm{HPV}$ indicators in some degree.

\section{Materials and Methods}

\subsection{Study Population}

This study is a sub-analysis of the Text To Test (T2T) study, which investigated the impact of automated text message reminders on testing of HIV and other STIs among MSM in China [37]. The T2T study is a randomized controlled trial which enrolled participants from sexual health clinics and MSM community organizations in three large cities (Guangzhou, Shenzhen, and Wuxi) in China between 1 January 2017 and 31 August 2017. Briefly, eligible men in the T2T study were at least 18 years old, had anal sex with 2 or more men in their lifetime or had an STI history, possessed a mobile phone, resided in the study city for the next 12 months, and were willing to undergo a questionnaire and HIV/STIs testing. Men were excluded from the T2T study if they had severe psychiatric illnesses or could not read or speak Chinese language. Participants were randomized into an intervention group and a control group, and were followed up for 12 months. MSM in the intervention group received text messages monthly reminding them to test for HIV/STIs. The control group 
received no reminders. In the original sample size calculation, a sample size of $300 \mathrm{MSM}$ in the intervention group and $300 \mathrm{MSM}$ in the control group would provide $90 \%$ power to detect a $15.0 \%$ (from $50 \%$ to $65 \%$ ) difference in the proportion of HIV testing in the past 12 months between the two groups, taking into account $30 \%$ lost to follow-up at 12 months. We provided HPV testing for participants at baseline and 12 months. All participants in the intervention group or control group volunteered to undergo HPV testing at baseline or at the 12-month visit. In this sub-analysis, men were included if they underwent testing for HPV on two occasions: one at baseline and another at 12 months.

\subsection{Data and Specimen Collection}

At each visit, participants completed a self-administered questionnaire that collected data on sociodemographic characteristics (including age, site of enrollment, marriage status, educational level, salary, profession, and smoking status), sexual behaviors (including time since first anal sex, sexual role in anal sex during the follow-up period, number of sexual partners, and condom use status), and drug use status. A sample of venous blood (5 mL) was collected to test for HIV. An anal brush of exfoliated cells was collected at each visit and was sent for HPV DNA testing and genotyping. Anal HPV testing was performed with a soft cytology brush (Hybribio, Chaozhou, China) inserted $3 \mathrm{~cm}$ into the anal canal and rotated ten times clockwise and ten times counterclockwise. Anal swabs were stored in $3 \mathrm{~mL}$ of sample transport medium for the Hybribio 37 HPV GenoArray Diagnostic Kit (Hybribio, Guangzhou, China). Blood samples and exfoliated cell samples were stored at $-20{ }^{\circ} \mathrm{C}$ and $2-8{ }^{\circ} \mathrm{C}$, respectively, before further processing.

\subsection{HPV Detection and Genotyping}

HPV DNA testing and genotyping were performed using the 37 HPV GenoArray Diagnostic Kit (Hybribio, Chaozhou, China) in accordance with manufacturer instructions. Amplification of HPV L1 gene fragments was performed using the Life ECO Gene Amplification Instrument (Bioer, Hangzhou, China). HPV genotyping was performed using HPV Hybridization Reagents and the Nucleic Acid Hybridization System for Medical Use (Hybribio, Chaozhou, China) to detect $37 \mathrm{HPV}$ genotypes, including 13 high-risk genotypes $(16,18,31,33,35,39,45,51,52,56,58,59$, and 68) and 24 low-risk genotypes $(6,11,26,34,40,42,43,44,53,54,55,57,61,66,67,69,70,71,72,73,81,82,83$, and 84) for carcinogenicity [38].

\subsection{Statistical Analyses}

HPV positivity of a specimen was defined as detection of $\geq 1 \mathrm{HPV}$ genotype. High-risk genotype positivity of a specimen was defined as detection of $\geq 1$ of any high-risk genotype, and low-risk genotype positivity of a specimen was defined as detection of $\geq 1$ of any low-risk genotype. Incident HPV positivity was defined as the same HPV type detected at 12 months in men who had a negative HPV test at baseline. HPV clearance was defined as the absence of the same HPV type at 12 months in men who had a positive HPV test at baseline. Persistent infection of individual HPV genotypes in this study was identified as the same HPV genotype detected at both baseline and follow-up visits, and persistent infection of any HPV genotype was identified as one or more HPV genotypes detected at both baseline and follow-up visits [26,35].

Rates of HPV incidence, clearance, and persistence were calculated as the respective number of incident, cleared, and persistent infections divided by total person-time at risk. Corresponding 95\% confidence intervals (CI) were calculated presuming a Poisson distribution. The events of incidence and clearance in this study were calculated based on infections rather than participants. Person months $(\mathrm{pm})$ were calculated as the period from the baseline visit during which a participant was recruited to the date of the follow-up visit conducted 12 or more months after recruitment. For HPV incident infection of any/any high-risk/any low-risk/9V/4V/6 or 11 genotypes, no individual was infected with all the genotypes at baseline; therefore, one individual was likely to acquire incident infections 
with other genotypes included in these categories, and all the participants were included in the calculation of person months. For HPV incident infection of individual genotypes, the period of follow-up of one participant was included only when he was not infected with one specific genotype at baseline. For HPV clearance, individuals infected with one or more genotypes of any/any $\mathrm{HR} /$ any $\mathrm{LR} / 9 \mathrm{~V} / 4 \mathrm{~V} / 2 \mathrm{~V} / 6$ or 11 at baseline supply person months for corresponding indicators, and individuals infected with one specific genotype at baseline supply person months for corresponding genotype.

In order to evaluate potential bias due to loss to follow-up, sociodemographic and behavioral characteristics of MSM who completed two HPV tests and MSM only tested at baseline were compared using simple descriptive statistics and Fisher's exact test. Median and interquartile range (IQR) were used to describe continuous variables, and proportions were used to describe categorical variables. Generalized estimating equations (GEE) logistic regression with robust standard errors and an exchangeable correlation structure was used to investigate the correlates for incident and cleared anal HPV infection. Variables found statistically significantly associated with outcomes in the previous literature or with a $p$-value $<0.2$ in univariate analyses, entered into the multivariable models to estimate the adjusted odds ratios (OR), as well as their 95\% CIs were as follows: age at recruitment, marriage status, educational level, profession, number of sexual partners during follow-up, time since first anal sex, sexual role in anal sex, and HIV status for HPV incidence; and age at recruitment, site of enrollment, marriage status, profession, number of sexual partners during follow-up, time since first anal sex, sexual role in anal sex, and HIV status for HPV clearance. Rates of HPV incidence, clearance, and persistence were calculated across age groups. Age was divided into 4 groups ( $<23$ years, 23-27 years, 28-32 years, and $\geq 33$ years), using cutoff points close to quartiles, and at least 30 individuals were contained in each group to assure a relatively accurate estimation for HPV indicators. All statistical analyses were performed using Stata SE version 15 (Stata Intercooled, College Station, TX, USA) and R 3.6.3 (R Core Team, Vienna, Austria).

\section{Conclusions}

This study provides an assessment of HPV incidence, persistence, and clearance for 37 genotypes among MSM, employing multiple methods to recruit participants in three metropolitan cities in China. It is important in informing HPV transmission modelling among MSM and supporting policy making against HPV epidemic. Our study builds on previous prevalence studies of HPV infection among MSM in China. We have found incident HPV infection is common among MSM in China. HPV16 and HPV18 have high rates of incident infection, and HPV6 and HPV16 have high rates of persistent infection, which suggests the need for HPV vaccination among this population. Young MSM are at disproportionately high risk for HPV infection and should be given the priority in HPV vaccination campaigns. Further studies are needed to clarify incidence, persistence, and clearance of HPV infection at other anatomical sites and the burden of HPV-related diseases among MSM, using larger sample size and long-term follow-up.

Supplementary Materials: The following supporting information can be downloaded at: https: / / www.mdpi.com/article/10.3390/pathogens11030314/s1, Table S1: Demographic characteristics and sexual behaviors among men who have sex with men.

Author Contributions: Conceptualization, H.Z. and Y.Z.; methodology, G.L.; software, Y.Z.; validation, Y.-F.L., P.L. and Z.W.; formal analysis, Y.Z.; investigation, L.F.; resources, X.M., J.D., Y.L., Z.L.; data curation, H.Z. and G.L.; writing —original draft preparation, Y.Z.; writing—review and editing, X.Z.; visualization, T.T.; supervision, H.Z.; project administration, H.Z.; funding acquisition, H.Z. All authors have read and agreed to the published version of the manuscript. 
Funding: This study was supported by the Natural Science Foundation of China Excellent Young Scientists Fund [82022064], Natural Science Foundation of China International/Regional Research Collaboration Project [72061137001], and Special Support Plan for High-Level Talents of Guangdong Province [2019TQ05Y230]. All funding parties did not have any role in the design of the study or in the explanation of the manuscript data, with all authors critically reviewing the paper.

Institutional Review Board Statement: The study was conducted according to the guidelines of the Declaration of Helsinki, and approved by the Human Research Ethics Committee (HREC) of the University of New South Wales (No. HC16803).

Informed Consent Statement: Informed consent was obtained from all participants involved in the study.

Data Availability Statement: All data generated or analyzed during this study are included in this published article and its Supplementary files.

Acknowledgments: The authors extend their sincere gratitude to the following organizations for their support: Wuxi Municipal Centre for Disease Control and Prevention, Shenzhen Nanshan Center for Chronic Disease Control, and Dermatology Hospital of Southern Medical University.

Conflicts of Interest: The authors declare no conflict of interest.

\section{References}

1. Jin, F.; Vajdic, C.M.; Law, M.; Amin, J.; van Leeuwen, M.; McGregor, S.; Poynten, I.M.; Templeton, D.J.; Grulich, A.E. Incidence and time trends of anal cancer among people living with HIV in Australia. AIDS 2019, 33, 1361-1368. [CrossRef] [PubMed]

2. Heer, E.; Hackl, M.; Ferlitsch, M.; Waldhoer, T.; Yang, L. Trends in incidence of anal cancer in Austria, 1983-2016. Wiener Klinische Wochenschrift 2020, 132, 438-443. [CrossRef] [PubMed]

3. Shiels, M.S.; Kreimer, A.R.; Coghill, A.E.; Darragh, T.M.; Devesa, S.S. Anal Cancer Incidence in the United States, 1977-2011: Distinct Patterns by Histology and Behavior. Cancer Epidemiol. Prev. Biomark. 2015, 24, 1548-1556. [CrossRef] [PubMed]

4. Nielsen, A.; Munk, C.; Kjaer, S.K. Trends in incidence of anal cancer and high-grade anal intraepithelial neoplasia in Denmark, 1978-2008. Int. J. Cancer 2012, 130, 1168-1173. [CrossRef] [PubMed]

5. Wilkinson, J.R.; Morris, E.J.A.; Downing, A.; Finan, P.J.; Aravani, A.; Thomas, J.D.; Sebag-Montefiore, D. The rising incidence of anal cancer in England 1990-2010: A population-based study. Colorectal Dis. 2014, 16, O234-O239. [CrossRef]

6. Guren, M.G.; Aagnes, B.; Nygård, M.; Dahl, O.; Møller, B. Rising Incidence and Improved Survival of Anal Squamous Cell Carcinoma in Norway, 1987-2016. Clin. Colorectal Cancer 2019, 18, e96-e103. [CrossRef]

7. Lin, C.; Franceschi, S.; Clifford, G.M. Human papillomavirus types from infection to cancer in the anus, according to sex and HIV status: A systematic review and meta-analysis. Lancet Infect. Dis. 2018, 18, 198-206. [CrossRef]

8. Saunders, C.L.; Meads, C.; Abel, G.A.; Lyratzopoulos, G. Associations Between Sexual Orientation and Overall and Site-Specific Diagnosis of Cancer: Evidence From Two National Patient Surveys in England. J. Clin. Oncol. 2017, 35, 3654-3661. [CrossRef]

9. Frisch, M.; Biggar, I.J.; Goedert, J.J. Human papillomavirus-associated cancers in patients with human immunodeficiency virus infection and acquired immunodeficiency syndrome. J. Natl. Cancer Inst. 2000, 92, 1500-1510. [CrossRef]

10. Looker, K.J.; Rönn, M.M.; Brock, P.M.; Brisson, M.; Drolet, M.; Mayaud, P.; Boily, M.C. Evidence of synergistic relationships between HIV and Human Papillomavirus (HPV): Systematic reviews and meta-analyses of longitudinal studies of HPV acquisition and clearance by HIV status, and of HIV acquisition by HPV status. J. Int. AIDS Soc. 2018, 21, e25110. [CrossRef]

11. Mooij, S.H.; van Santen, D.K.; Geskus, R.B.; van der Sande, M.A.B.; Coutinho, R.A.; Stolte, I.G.; Snijders, P.J.F.; Meijer, C.J.L.M.; Speksnijder, A.G.C.L.; de Vries, H.J.C.; et al. The effect of HIV infection on anal and penile human papillomavirus incidence and clearance: A cohort study among MSM. AIDS 2016, 30, 121-132. [CrossRef] [PubMed]

12. Clifford, G.M.; Georges, D.; Shiels, M.S.; Engels, E.A.; Albuquerque, A.; Poynten, I.M.; de Pokomandy, A.; Easson, A.M.; Stier, E.A. A meta-analysis of anal cancer incidence by risk group: Toward a unified anal cancer risk scale. Int. J. Cancer 2021, $148,38-47$. [CrossRef] [PubMed]

13. Marra, E.; Lin, C.; Clifford, G.M. Type-Specific Anal Human Papillomavirus Prevalence Among Men, According to Sexual Preference and HIV Status: A Systematic Literature Review and Meta-Analysis. J. Infect. Dis. 2019, 219, 590-598. [CrossRef] [PubMed]

14. Ma, X.; Wang, Q.; Ong, J.J.; Fairley, C.K.; Su, S.; Peng, P.; Jing, J.; Wang, L.; Soe, N.N.; Cheng, F.; et al. Prevalence of human papillomavirus by geographical regions, sexual orientation and HIV status in China: A systematic review and meta-analysis. Sex Transm. Infect. 2018, 94, 434-442. [CrossRef]

15. Palefsky, J.M.; Giuliano, A.R.; Goldstone, S.; Moreira, E.D.; Aranda, C.; Jessen, H.; Hillman, R.; Ferris, D.; Coutlee, F.; Stoler, M.H.; et al. HPV vaccine against anal HPV infection and anal intraepithelial neoplasia. N. Engl. J. Med. 2011, 365, 1576-1585. [CrossRef]

16. Petrosky, E.; Bocchini, J.A., Jr.; Hariri, S.; Chesson, H.; Curtis, C.R.; Saraiya, M.; Unger, E.R.; Markowitz, L.E. Use of 9-valent human papillomavirus (HPV) vaccine: Updated HPV vaccination recommendations of the advisory committee on immunization practices. MMWR Morb. Mortal Wkly. Rep. 2015, 64, 300-304. 
17. Petit, B.; Epaulard, O. Men having sex with men and the HPV vaccine in France: A low vaccine coverage that may be due to its infrequent proposal by physicians. Vaccine 2020, 38, 2160-2165. [CrossRef]

18. Edelstein, M.; Iyanger, N.; Hennessy, N.; Mesher, D.; Checchi, M.; Soldan, K.; McCall, M.; Nugent, J.; Crofts, J.; Lo, J.; et al. Implementation and evaluation of the human papillomavirus (HPV) vaccination pilot for men who have sex with men (MSM), England, April 2016 to March 2017. Eurosurveillance 2019, 24, 44-50. [CrossRef]

19. Chow, E.P.F.; Machalek, D.A.; Tabrizi, S.N.; Danielewski, J.A.; Fehler, G.; Bradshaw, C.S.; Garland, S.M.; Chen, M.Y.; Fairley, C.K. Quadrivalent vaccine-targeted human papillomavirus genotypes in heterosexual men after the Australian female human papillomavirus vaccination programme: A retrospective observational study. Lancet Infect. Dis. 2017, 17, 68-77. [CrossRef]

20. Geskus, R.B.; González, C.; Torres, M.; Del Romero, J.; Viciana, P.; Masiá, M.; Blanco, J.R.; Iribarren, M.; De Sanjosé, S.; HernándezNovoa, B.; et al. Incidence and clearance of anal high-risk human papillomavirus in HIV-positive men who have sex with men: Estimates and risk factors. AIDS 2016, 30, 37-44. [CrossRef]

21. Hernandez, A.L.; Efird, J.T.; Holly, E.A.; Berry, J.M.; Jay, N.; Palefsky, J.M. Incidence of and risk factors for type-specific anal human papillomavirus infection among HIV-positive MSM. AIDS 2014, 28, 1341-1349. [CrossRef] [PubMed]

22. Zou, H.; Tabrizi, S.N.; Grulich, A.E.; Garland, S.M.; Hocking, J.S.; Bradshaw, C.S.; Morrow, A.; Prestage, G.; Cornall, A.M.; Fairley, C.K.; et al. Early acquisition of anogenital human papillomavirus among teenage men who have sex with men. J. Infect. Dis. 2014, 209, 642-651. [CrossRef] [PubMed]

23. Yunihastuti, E.; Teeratakulpisarn, N.; Jeo, W.S.; Nilasari, H.; Rachmadi, L.; Somia, I.K.A.; Sukmawati, M.D.D.; Amijaya, K.A.T.; Yee, I.A.; Hairunisa, N.; et al. Incidence, clearance, persistence and factors related with high-risk anal HPV persistence in South-East Asian MSM and transgender women. AIDS 2020, 34, 1933-1941. [CrossRef] [PubMed]

24. Ong, J.J.; Walker, S.; Grulich, A.; Hoy, J.; Read, T.R.; Bradshaw, C.; Chen, M.; Garland, S.M.; Cornall, A.; Hillman, R. Incidence, clearance, and persistence of anal human papillomavirus in men who have sex with men living with human immunodeficiency virus: Implications for human papillomavirus vaccination. Sex. Transm. Dis. 2019, 46, 229-233. [CrossRef] [PubMed]

25. Donà, M.G.; Vescio, M.F.; Latini, A.; Giglio, A.; Moretto, D.; Frasca, M.; Benevolo, M.; Rollo, F.; Colafigli, M.; Cristaudo, A.; et al. Anal human papillomavirus in HIV-uninfected men who have sex with men: Incidence and clearance rates, duration of infection, and risk factors. Clin. Microbiol. Infect. 2016, 22, 1004.e1-1004.e7. [CrossRef]

26. Cotte, L.; Veyer, D.; Charreau, I.; Péré, H.; Cua, E.; Carette, D.; Chas, J.; Capitant, C.; Chidiac, C.; Fléjou, J.F.; et al. Prevalence and incidence of HPV infection in men having sex with men enrolled in a PrEP study: A sub-study of the ANRS IPERGAY trial. Clin. Infect Dis. 2020. [CrossRef]

27. Zhou, Y.; Lin, Y.-F.; Meng, X.; Duan, Q.; Wang, Z.; Yang, B.; Zheng, H.; Li, P.; Li, M.; Lu, Y.; et al. Anal human papillomavirus among men who have sex with men in three metropolitan cities in southern China: Implications for HPV vaccination. Vaccine 2020, 38, 2849-2858. [CrossRef]

28. Wei, F.; Guo, M.; Huang, S.; Li, M.; Cui, X.; Su, Y.; Wu, X.; Ma, X.; Zheng, Y.; Huang, Y.; et al. Sex Differences in the Incidence and Clearance of Anogenital Human Papillomavirus Infection in Liuzhou, China: An Observational Cohort Study. Clin. Infect. Dis. 2020, 70, 82-89. [CrossRef]

29. Zhang, C.; Liu, F.; Pan, Y.; Deng, Q.; Li, X.; He, Z.; Liu, M.; Ning, T.; Guo, C.; Liang, Y.; et al. Incidence and clearance of oral human papillomavirus infection: A population-based cohort study in rural China. Oncotarget 2017, 8, 59831-59844. [CrossRef]

30. Marra, E.; Kovaleva, A.; Bruisten, S.M.; Vermeulen, W.; Boyd, A.; Schim van der Loeff, M.F. Incidence and Clearance of Anal Highrisk Human Papillomavirus Infections and Their Determinants Over 5 Years Among Human Immunodeficiency Virus-negative Men Who Have Sex With Men. Clin. Infect. Dis. 2019, 68, 1556-1565. [CrossRef]

31. Alberts, C.J.; Heard, I.; Canestri, A.; Marchand, L.; Fléjou, J.-F.; Piroth, L.; Ferry, T.; Didelot, J.-M.; Siproudhis, L.; Henno, S.; et al. Incidence and Clearance of Anal Human Papillomavirus (HPV)-16 and HPV-18 Infection, and Their Determinants, Among Human Immunodeficiency Virus-Infected Men Who Have Sex With Men in France. J. Infect. Dis. 2020, 221, 1488-1493. [CrossRef] [PubMed]

32. Phanuphak, N.; Teeratakulpisarn, N.; Pankam, T.; Kerr, S.J.; Barisri, J.; Deesua, A.; Rodbamrung, P.; Hongchookiat, P.; Chomchey, N.; Phanuphak, P. Anal human papillomavirus infection among Thai men who have sex with men with and without HIV infection: Prevalence, incidence, and persistence. J. Acquir. Immune Defic. Syndr. 2013, 63, 472. [CrossRef]

33. Wei, F.; Su, Y.; Yao, X.; Cui, X.; Bian, L.; Yin, K.; Yu, X.; Zhuang, C.; Bi, Z.; Huang, S.; et al. Sex differences in the incidence and clearance of anal human papillomavirus infection among heterosexual men and women in Liuzhou, China: An observational cohort study. Int. J. Cancer 2019, 145, 807-816. [CrossRef] [PubMed]

34. Zhou, Y.; Lin, Y.-F.; Gao, L.; Dai, J.; Luo, G.; Li, L.; Yuan, T.; Li, P.; Zhan, Y.; Gao, Y.; et al. Human papillomavirus prevalence among men who have sex with men in China: A systematic review and meta-analysis. Eur. J. Clin. Microbiol. Infect. Dis. 2021, 40, 1357-1367. [CrossRef] [PubMed]

35. Nyitray, A.G.; Carvalho da Silva, R.J.; Baggio, M.L.; Smith, D.E.; Abrahamsen, M.; Papenfuss, M.; Lin, H.-Y.; Quiterio, M.; Salmerón, J.; Lazcano-Ponce, E.; et al. Six-month incidence, persistence, and factors associated with persistence of anal human papillomavirus in men: The HPV in men study. J. Infect. Dis. 2011, 204, 1711-1722. [CrossRef] [PubMed]

36. Zou, H.; Xu, J.; Hu, Q.; Yu, Y.; Fu, G.; Wang, Z.; Lu, L.; Zhuang, M.; Chen, X.; Fu, J.; et al. Decreasing age at first anal intercourse among men who have sex with men in China: A multicentre cross-sectional survey. J. Int. AIDS Soc. 2016, 19, 20792. [CrossRef] 
37. Zou, H.; Meng, X.; Grulich, A.; Huang, S.; Jia, T.; Zhang, X.; Luo, Z.; Ding, Y.; Yang, L.; Huang, J.; et al. A randomised controlled trial to evaluate the impact of sexual health clinic based automated text message reminders on testing of HIV and other sexually transmitted infections in men who have sex with men in China: Protocol for the T2T Study. BMJ Open 2017, 7, e015787. [CrossRef]

38. World Health Organization. Human Papillomaviruses. Available online: https://monographs.iarc.who.int/wp-content/ uploads/2018/06/mono100B-11.pdf (accessed on 9 January 2022). 